\title{
The Possibilities of Using the Shalom H. Schwartz's Values Questionnaire for the Search of Value-Semantic Justifications of Organizational Changes
}

\author{
Konstantin Tsaranov ${ }^{1}$, Aleksey Tarbastaev ${ }^{1}$, Elena Klimova ${ }^{2},{ }^{*}$ Olga Komolova ${ }^{1}$ \\ ${ }^{1}$ Moscow Metropolitan Governance Yury Luzhkov University, Russia \\ ${ }^{2}$ Moscow Regional State University. Russia \\ *Email: em.klimova@mgou.ru
}

\begin{abstract}
Theoretical analysis of the organisation's value management problem revealed contradictions between the valuesemantic justifications of changes declared by the head and the existing system of values reported by the team members. The main reason for this problem may be the lack of objectified information about employees' value profile. The study aimed to determine the possibilities of using the SVS (Schwartz Value Survey) and PVQ (Portrait Values Questionnaire) questionnaires to assess value orientations' interrelationships in production groups to develop further recommendations for managers in justifying organizational changes. It is shown that cluster analysis of diagnostic results using the SVS (Schwartz Value Survey) and PVQ (Portrait Values Questionnaire) questionnaires allows to identify the maximum values relative to representatives of professions in various industries and determine the significance of the selected values in the context of "imposed values". The study involved 42 respondents (the working heads of medical and military institutions). All respondents were divided into 3 subgroups according to the importance of the normative ideals of the value orientation "Safety" in guiding their actions. The results of the study allow us to formulate a system of recommendations for managers of organisations to justify organizational changes, through the implementation of several stages: building a structural model of an ideal organizational culture; determining the algorithm of actions for organizational changes in the context of value management, developing a Roadmap; planning resources (intellectual, material). The primary attention in the formation of organizational culture should be paid to employees' already formed values. The manager's conversations with employees focused on leading values will attract their attention and quickly develop the "declared values" that form organizational culture.
\end{abstract}

Keywords: Value orientations of the individual, Value questionnaire of Sh. Schwartz, Organizational culture, Patient-centred organizational culture, Normative ideals, Value-semantic justification.

\section{INTRODUCTION}

Value orientations of an individual are the essential components of the morality of society. They are anchored by life experience.

From the P. Schmidt's point of view that was presented in the scientific seminar "Culture matters" "the set of established, fixed value orientations form a kind of system of personal coordinates that ensures the stability and continuity of a certain type of behaviour and activity, expressed in the direction of human needs and interests" [1].

K. Boehnke notes that in "normal circumstances, people's value orientations remain relatively stable throughout adult life" [2].

A.Yu. Ogorodnikov in his work "The study of internalisation of modern youth values, as information resource management" concludes that the system of value orientations determines the content side orientation of an individual and is the basis of its relations to the 
surrounding world, to other people, the basis of ideology, concept and "philosophy of life" [3].

Sh.H. Schwartz, W. Bilsky believe that for individuals, values represent "motivational goals that serve as guiding principles in their lives" [4].

The organisation's values are a symbiosis of each employee's values, manifested in all aspects of the team's activities.

Value orientation in the management of an organisation is a way to link goals and priorities so that, guided by them, employees can consistently and predictably achieve the tasks facing the business as a whole [5].

\section{STATEMENT OF THE SCIENTIFIC PROBLEM}

Using the value management of an organisation is the contradiction of the value-semantic justifications of changes declared by the head and the established value system reported by the team representatives entrusted to him/her. It cannot be excluded that the leading cause of this problem maybe the lack of objectified information about employees' value profile.

Under this problem, we formulated the purpose of the study: to determine the possibilities of using the SVS (Schwartz Value Survey) and PVQ (Portrait Values Questionnaire) questionnaires to assess the interrelationships of value orientations in production groups to further develop recommendations to managers in the formation of the organizational culture of the institution.

To achieve this goal, it is necessary to solve several consecutive tasks:

1) to identify the relationship between the indicators of the questionnaires on the example of two teams;

2) based on the obtained diagnostic data, to develop an algorithm of actions for managers to implement organizational changes in the context of value management.

The study of personal value orientations attracted the attention of both domestic and foreign researchers:

- the fullness of personal values, the hierarchical structure of the individual value system, the influence of various factors on the formation and change of the value system $[6,7,8]$

- the problem of value orientations of Russian youth

- values and self-attitude at the stage of youth socialisation [11]
- target transformation of value orientations of a modern student's personality [12]

- the system of personal values in the perspective of tolerance [13]

- in the context of socio-cultural and individual differences [14]

- to identify indicators of cross-cultural values, personality and beliefs [15]

- on behavioural disinhibition and social value orientations [16]

- connection with interest and other motivational concepts [17]

- value orientations of a doctor as a predictor of the effectiveness of a medical organisation [18]

However, we have not found studies that would aim to find solutions to prevent value conflicts between managers and subordinates by preparing managers to plan the implementation of changes, considering the value-semantic justification of actions and arguments that will be translated into messages (appeals) to labour collectives.

The main categories for in-depth analysis of personal value orientations are normative ideals, declared values.

Under the values, Sh. Schwartz (Shalom H. Schwartz) meant "known" needs, the change of which is influenced by the external environment, the mentality of the individual [19]

When analysing and interpreting the results of the Schwartz Value Orientation Questionnaire, two types of values are diagnosed:

1 normative ideals, values of the individual at the level of beliefs,

2 the structure of values that most strongly affects the subject of professional activity.

The difference in indicators by types of values reflects the influence exerted on an individual by society.

In the light of the cultural and historical paradigm, E.Yu. Patyaeva [20] - solving the problem of substantiating the value-semantic foundations of activity requires the manager to know first of all his normative ideals, target audiences, and higher-level managers if the manager is not the owner of the organisation.

\section{RESEARCH METHODS}

The study of using the value questionnaire of Sh. Schwartz's possibility of finding value-semantic justifications for organizational changes was conducted in 2020 based on medical and military institutions. 
The study involved 42 respondents (working managers of medical and military institutions), and a spontaneous survey on paper and electronic versions of the questionnaires SVS-57 and PQV-40 (Schwartz) was conducted.

The primary analysis was carried out using the $\mathrm{K}$ Means algorithm; the average silhouette index is 0.512 . The three most important indicators that determine clustering are identified: the normative ideals of value orientation " Universalism" (0.14), "Independence" (0.1), and "Security" (0.1). Then, the CHAID regression tree algorithm was applied, where the indicator "Normative ideals of value orientation Universalism" was chosen as the target indicator. Data processing was carried out in the program "IBM SPSS Modeler 18.2.2".

\section{RESEARCH RESULTS}

All respondents were divided into 3 subgroups according to the importance of the normative ideals of the value orientation "Safety" in guiding their actions. The degree of significance of this value varies from $78 \%$ to $88 \%$. The level of statistical significance $(0.833, \mathrm{p}$ $<0.01)$.

The division by industry was as follows: two subgroups dominated by either medical personnel or the military, and the third one was mixed $(\approx 50 / 50)$.

As a study result, the rating of value orientations for each of the selected subgroups was determined (table 1)

The value of "kindness" is significant for all groups. The most important values in the rating for the groups "military" and "medical professionals" are "universalism" and "independence", the least significant are "hedonism" and "traditions."

The applied algorithm of the CHAID regression tree, where the indicator "Normative ideals of value orientation Universalism" was chosen as the target indicator, showed:

The more respondents declare that it is essential for them to be guided by the normative ideals of the value orientation "Universalism", the more they claim that they are conducted in their actions by the normative ideals of the value orientation "Security" (Figure 1). The next significant values for the study sample were independence and power.

The more respondents declare that it is vital for them to be guided by the normative ideals of the value orientation "Security". The more they claim that they are conducted in their actions by the normative ideals of the value orientations "Power" (subgroup "Doctors") and "Independence" (mixed subgroup).

"Conformity" completes the list of the most significant values.

The more respondents declare that they need to be guided by the normative ideals of value orientations of "Power" and "Autonomy" (the importance of more than $78 \%$, ) the more they declare the leadership in their actions of the normative ideals of value orientations "Conformity" (a subset of "Doctors" and a mixed subgroup).

The value of "Tradition" was reflected in the mixed group of respondents.

The more respondents declare that they need to be guided by the normative ideals of the value orientations of "Autonomy" (on the importance level between 70 and $78 \%$ ), the more they declare the leadership in their actions of the normative ideals of value orientations "Traditions" (figure 1)

In connection with the increase in personal and situational anxiety among medical workers working in conditions of increased danger caused by the spread of COVID-19, which leads to a change in the value

Table 1. Rating of value orientations

\begin{tabular}{|c|c|c|}
\hline Military & A mixed group & Medical professionals \\
\hline Security & Security & Self-Direction \\
\hline Benevolence & Benevolence & Benevolence \\
\hline Self-Direction & Universalism & Achievement \\
\hline Conformity & Self-Direction & Security \\
\hline Universalism & Conformity & Universalism \\
\hline Achievement & Achievement & Power \\
\hline Stimulation & Hedonism & Stimulation \\
\hline Hedonism & Power & Tradition \\
\hline Tradition & Stimulation & Hedonism \\
\hline Power & Tradition & \\
\hline
\end{tabular}


orientations of the individual, the results obtained in the group "medical professionals" were of particular interest to us. It turned out that the most significant value orientations are "independence", "kindness" and achievements", the least significant are "stimulation", "traditions" and "hedonism". The leading value orientations of employees assume the implementation of the medical organisation's primary mission - the priority of preserving or restoring the patient's health. In this context, we consider it appropriate to introduce into scientific circulation for medical organisations the concept of "patient-centred organizational culture" - a system of relationships, the purpose of which is to create and transfer cultural artefacts to increase the level of awareness and involvement in the treatment process of all subjects of medical interaction.

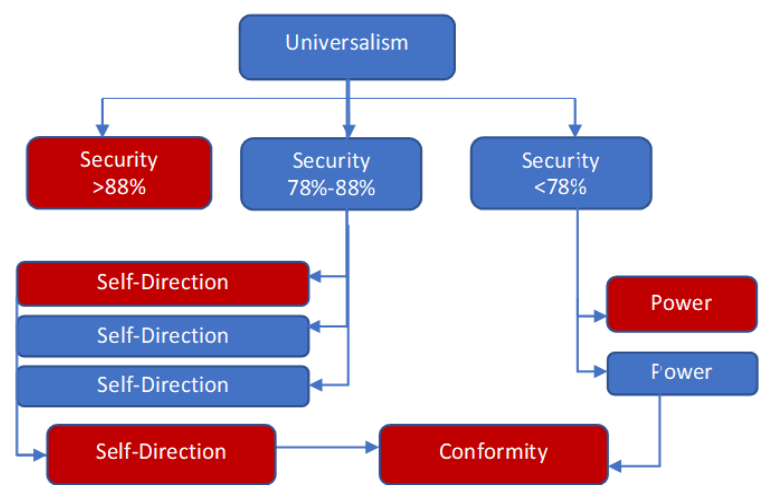

Figure 1 Distribution of normative ideals by groups regarding the importance of normative ideals of the value orientation "Security" for them.

Note. 3 leading and 3 least significant value orientations are highlighted in colour.

By cultural artefacts, we mean material and nonmaterial information carriers of sensory consciousness and experience that contribute to a conscious and appropriate change in the social roles of medical interaction subjects.

The planning stage for the formation of an organizational culture consists of the following steps:

- building a structural model of an ideal organizational culture;

- definition of the algorithm of actions, development of the Road map;

- planning of resources (intellectual, material).

\section{CONCLUSION}

Thus, the purpose of the study was achieved. We consider it necessary to use the SVS (Schwartz Value Survey) and PVQ (Portrait Values Questionnaire) questionnaires to determine the interrelationships of value orientations in organisations' employees to further develop recommendations managers in the formation of the organizational culture of the institution.

Presented qualitative analysis of the individual's value orientations according to the "Value questionnaire" method of Sh. Schwartz made it possible to introduce the concept of "patient-centred organizational culture" into scientific circulation for medical organisations and offer a universal system of recommendations for the heads of institutions to form an organizational culture that best corresponds to the tasks and goals of the organisation.

The primary attention in the formation of organizational culture should be paid to employees' already formed values. The manager's conversations with employees focused on leading values will attract their attention and quickly develop the "declared values" that form organizational culture.

\section{REFERENCES}

[1] P. Schmidt, Inglehart and Schwartz approaches in comparison: measurements and theoretical predictions, 2011. Retrieved from: https://scr.hse.ru/en/news/29248810.html

[2] K. Boehnke, Does COVID-19 propel value change: A comparison of Germany and the United Kingdom? 2020. Retrieved from: https://scr.hse.ru/en/news/414974428.html

[3] A.Yu. Ogorodnikov, Research of internalisation of modern youth values as an information resource of management, Sociology of Power 5 (2008) 91-97 (In Russ.).

[4] Sh.H. Schwartz, W. Bilsky, Toward a theory of the Universal Content and Structure of Values: Extensions and Cross-Cultural Replications, Journal of Personality and Social Psychology, Voi. 58, Iss. $5,1990$.

[5] What values should your company's employees share. Retrieved from: https://hrportal.ru/article/kakie-cennosti-dolzhny-razdelyatsotrudniki-vashey-kompanii

[6] A.I. Veretskaya, Values of higher education in the structure of students' lifestyle, Fifth Kovalev Readings, 2010, pp. 674-676 (In Russ.).

[7] N.I. Lapin, Values as components of modern Russia's socio-cultural evolution, Sociological Research 5 (1994) 3-8 (In Russ.).

[8] V.A. Yadov, Self-regulation and prediction of social behaviour of the individual: A Dispositional concept. Moscow: TSPiM, 2013, 376 p. (In Russ.).

[9] I.A. Koch, L.A. Alekseeva, Professional-value orientations of student youth on the example of the study of priorities in the structure of terminal and 
instrumental life values of students, Social Management 4(53) (2018) 113-118 (In Russ.).

[10] Value orientations of Russian youth and state youth policy implementation: the results of the research monograph / under the general editorship of S.V. Chueva], GUU Publishing House, 2017, 131 p. (In Russ.).

[11] O.A. Tikhomandritskaya, N.G. Malysheva, Z. D. Shaekhov, N.A. Kabalnov, The problem of the relationship between personal values and psychological well-being in high school students, Psychological Research Vol. 11 Iss. 62 (2018) 9. Retrieved from: http://psystudy.ru/index.php/num/2018v11n62/165 1-tikhomandritskaya62.html

[12] A.V. Vnukov, Value orientations of a student's personality as regulators of social behaviour, Vestnik Universiteta 1 (2014) 237-239 (In Russ.).

[13] E.P. Belinskaya, The concept and value orientations of older adolescents in the context of rapid social changes, Bulletin of the Moscow University. Series 14: Psychology 4 (2004) 21 (In Russ.).

[14] H.C. Triandis, Introduction to Diversity in Clinical Psychology, 1998. Retrieved from https://doi.org/10.1016/B0080-4270(73)00103-6

[15] Ch. Chiu, Sh. I. Chia, W.W.N. Wan, Measures of Personality and Social Psychological Constructs, 2015. Retrieved from: https://doi.org/10.1016/B978-0-12-3869159.00022-X

[16] K. van den Bos, E.A. Lind, On Sense-Making Reactions and Public Inhibition of Benign Social Motives: An Appraisal Model of Prosocial Behavior, 2013. Retrieved from https://doi.org/10.1016/B978-0-12-4071889.00001-6

[17] Sh. Hidi, Interest, Psychology of., 2001. Retrieved from: $\quad$ https://doi.org/10.1016/B0-08-043076$\underline{7 / 01535-7}$

[18] K.N. Tsaranov, E.M. Klimova, T.V. Akimov, A.B. Swanski, A.G. Tarbastaev, Value orientations of a doctor as a predictor of the effectiveness of a medical organisation, Health Care Manager 9 (2020) 63-70 (In Russ.).

[19] Sh.H. Schwartz, A Value Priorities and Behavior: Applying a Theory of Integrated Value Systems, $1996 . \quad$ Retrieved from: https://www.researchgate.net/publication/2285995 59 Value Priorities and Behavior_Applying_a_T heory of Integrated Value Systems
[20] E.Yu. Patyaeva, System of socio-cultural motivation: a conceptual model, Bulletin of Moscow University. Series 14: Psychology 1 (2013) 24-41 (In Russ.). 